\title{
Synthesis of graphene foams and their sorption properties of n-hexane
}

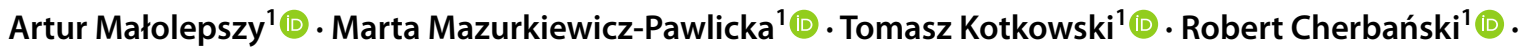 \\ Eugeniusz Molga ${ }^{1}$ (1) $\cdot$ Leszek Stobiński ${ }^{1,2}$
}

Published online: 11 March 2021

(c) The Author(s) 2021

\begin{abstract}
The influence of preparation conditions of the graphene foams on their physicochemical properties is shown. Different graphene aerogels were obtained from various graphene oxide water suspensions using the hydrothermal method (with or without the addition of acrylic microemulsion and varying in drying time- 24 and $48 \mathrm{~h}$ ). Prolonged drying of the hydrogels resulted in smaller pores in the foams. The composition of graphene oxide (GO) and acrylic polymer water suspensions leads to the smallest surface area which is due to the closing of the pores of the composite structure. Thermal treatment of samples at $950{ }^{\circ} \mathrm{C}$ removed the polymer residues. The heating process increased the surface area and the total pore volume of all samples, which were used to test the graphene foams (GFs) for adsorption of n-hexane. These tests have shown that the most effective samples for $\mathrm{n}$-hexane adsorption were the samples where for the preparation of the composite GO and acrylic resin were used. The best of obtained samples adsorbed $415 \mathrm{mg} \mathrm{g}^{-1}$ of $\mathrm{n}$-hexane which is a better result than for activated carbon manufactured from natural cork. Further preparation and modification of graphene foams could result in a significant increase in their sorption properties and could be used for contaminated air purification in the nearest future.
\end{abstract}

Keywords Graphene $\cdot$ Graphene foam $\cdot$ Surface area $\cdot$ Acrylic resin $\cdot$ n-Hexane

\section{Introduction}

Graphene gained a lot of attention in recent years due to its unique properties, such as high mechanical strength, electrical and thermal conductivity or high specific surface area (up to $2630 \mathrm{~m}^{2} \mathrm{~g}^{-1}$ ) [1]. There are many different methods for obtaining graphene, such as mechanical graphite exfoliation [2] or oxidation of graphite [3, 4]. Graphite oxidation using Hummers', Brody's or Staudenmaier's method leads to formation of graphite oxide with high amount of oxygen functional groups, such as hydroxyl, carboxyl, or epoxide. Graphite oxide exfoliation by the ultrasonic treatment leads

Artur Małolepszy

artur.malolepszy@pw.edu.pl

Leszek Stobiński

http://www.nanomaterials.pl

1 Faculty of Chemical and Process Engineering, Warsaw University of Technology, Warynskiego 1, 00-645 Warsaw, Poland

2 NANOMATERIALS Leszek Stobinski, Wyszogrodzka 14/38, 03-337 Warsaw, Poland to a few layers graphene oxide (GO) with covalently bonded functional oxygen groups which can further be reduced to obtain reduced graphene oxide (rGO) [5, 6]. Due to its high surface area, graphene materials could be used as adsorbents for many different pollutants, such as dyes or volatile organic compounds (VOCs).

The emission of volatile organic compounds (VOCs) is a serious global environmental problem. The problem is regulated in the European Union by the Paints Directive [7] and the Industrial Emissions Directive [8]. In the EU, VOCs is defined as "any organic compound having an initial boiling point less than or equal to $250{ }^{\circ} \mathrm{C}$ measured at a standard atmospheric pressure of $101.3 \mathrm{kPa}$." [7].

In general, sorbents with high surface areas and high pore volumes are good candidates for VOCs adsorption. Three-dimensional (3D) porous graphene-based materials have a potential to meet these conditions as shown in the following examples. Adsorbent with surface area up to $3100 \mathrm{~m}^{2} \mathrm{~g}^{-1}$ was produced by $\mathrm{KOH}$ activation of microwave exfoliated graphene oxide [1]. Similar results were reported for thermally exfoliated GO after $\mathrm{KOH}$ activation [9]. The produced graphene-based material showed surface area of 
$3240 \mathrm{~m}^{2} \mathrm{~g}^{-1}$ and total pore volume of $2.23 \mathrm{~cm}^{3} \mathrm{~g}^{-1}$. Adsorbents with surface areas up to $\sim 1900 \mathrm{~m}^{2} \mathrm{~g}^{-1}$ and total pore volume up to $1.65 \mathrm{~cm}^{3} \mathrm{~g}^{-1}$ were also fabricated using the same method of $\mathrm{KOH}$ activation of exfoliated GO in another work [10]. These examples demonstrate significant potential of graphene-based materials in the field of environmental protection.

Despite the great potential of graphene-based materials, there are only a limited number of papers reporting on their adsorption properties of VOCs. To date, the following VOCs have been studied: acetaldehyde [11], acetone [12], benzene [13-16], butanone [14], ethanol [13], methane [10, 16-19], methylene chloride [20], toluene [11, 15]. Hexane is an aliphatic saturated hydrocarbon obtained from petroleum with a boiling point $68.73{ }^{\circ} \mathrm{C}$ [21]. In contrary to the polycyclic aromatic hydrocarbons (PAHs), n-hexane has no aromatic rings that could interact with graphite layers. Hexane is mainly used as a solvent, formulation additive in glues for shoes and leather products and can be found in petroleum and gasoline products [22]. Thus, it can be released to the environment through different pathways. It is very important to control the amount of hexane in the environment, because exposure to it may result in different health effects, such as vertigo, nausea, peripheral neuropathy or headaches [23].

In this paper we proposed the use of 3D graphene foams for $\mathrm{n}$-hexane adsorption tests. We studied different preparation processes and their effect on the structure, chemical composition, surface area and hexane sorption properties of the obtained graphene foams. The novelty of the proposed materials is connected to the use of polymer microemulsion to stabilize the graphene foam structure and increase the surface area. The preparation process of these materials is simple and scalable, which means it could be applied commercially for adsorption of VOCs, especially n-hexane.

\section{Experimental}

\subsection{Materials}

For the preparation of graphene oxide the following materials were used.

Sodium nitrate p.a. potassium permanganate p.a., sulfuric acid p.a. $98 \%$, hydrogen peroxide p.a. $30 \%$ were purchased from Alchem Grup sp. z o.o., Poland and graphite powder $\geq 99.5 \%$ purchased from Acros Organics. Acrylic microemulsion used for preparation of graphene foams was purchased from CTS Srl, Italy.

Nitrogen 6.0 (Messer, Poland) and helium 6.0 (Multax, Poland) were used to perform analyses in a surface characterization analyzer. For vapor analyses, n-hexane (CAS: 110-54-3; purity $\geq 99 \%$ ), purchased from Chempur (Poland), was used. A separate nitrogen gas cylinder (purity 5.0) was used with a degasser unit.

\subsection{Sample preparation}

\subsubsection{Synthesis of graphene oxide}

Graphene oxide was prepared using modified Hummers method [3] from pure graphite powder. In this method $4.7 \mathrm{~g}$ of sodium nitrate and $30 \mathrm{~g}$ of potassium permanganate were added to $10 \mathrm{~g}$ of graphite powder and $230 \mathrm{ml}$ of concentrated sulfuric acid (98\%) at the temperature below $10{ }^{\circ} \mathrm{C}$. Then the mixture was heated up to $35^{\circ} \mathrm{C}$ and kept under stirring for $2 \mathrm{~h}$. In the next step, $100 \mathrm{ml}$ of water was added, and the mixture temperature reached $\sim 100{ }^{\circ} \mathrm{C}$. Finally, the mixture was treated with $10 \mathrm{ml}$ of $\mathrm{H}_{2} \mathrm{O}_{2}$. For purification, the slurry was filtrated and washed with deionized water till the $\mathrm{pH}$ of the filtrate reached $\sim 6.5$.

\subsubsection{Preparation of graphene foams}

The sample GF $24 \mathrm{~h}$ was prepared by hydrothermal method in stainless steel autoclave (Carl Roth) of $250 \mathrm{ml} 1 \mathrm{wt} \%$ graphene oxide water suspension. The reaction was carried out for $2 \mathrm{~h}$ under the pressure of $20 \mathrm{bar}$ and the temperature reached $250{ }^{\circ} \mathrm{C}$. Obtained hydrogel was dried for $24 \mathrm{~h}$ at $20^{\circ} \mathrm{C}$. After that the hydrogel of partially reduced graphene oxide was frozen at $-20^{\circ} \mathrm{C}$. The sample GF $48 \mathrm{~h}$ was prepared in the same way as sample GF $24 \mathrm{~h}$ but the hydrogel after synthesis was dried for $48 \mathrm{~h}$ at $20^{\circ} \mathrm{C}$ and then was frozen at $-20{ }^{\circ} \mathrm{C}$.

The sample denoted as Acrylic/GF $24 \mathrm{~h}$ was prepared by mixing $242 \mathrm{ml}$ of $1 \mathrm{wt} \%$ graphene oxide water suspension and $8 \mathrm{ml}$ of $32 \mathrm{wt} \%$ acrylic microemulsion. The mixture was transferred to the glass reactor and placed in a stainless-steel autoclave. The reaction was carried out for $2 \mathrm{~h}$ under the pressure of $20 \mathrm{bar}$ and the temperature reached $250^{\circ} \mathrm{C}$. The sample was dried for $24 \mathrm{~h}$ at $20^{\circ} \mathrm{C}$ and frozen at $-20^{\circ} \mathrm{C}$ and was denoted as Acrylic/GF $24 \mathrm{~h}$.

All of the hydrogels (GF 24 h, GF 48 h, Acrylic/GF 24 h) were lyophilized using vacuum pump to obtain graphene foams.

2.2.2.1 Thermal treatments of the foams Lyophilized samples were transferred to the tube furnace and sintered at $950{ }^{\circ} \mathrm{C}$ for $1 \mathrm{~h}$ in an argon atmosphere. After the heating process the samples were additionally denoted as 950C.

\subsubsection{Graphene foams characterization}

The obtained graphene foams were analyzed by scanning electron microscopy (SEM), Raman and FT-IR spectroscopy. 
Raman spectroscopy measurements were performed on an InVia Raman microscope (Renishaw) using 514 nm laser. For each sample, the spectra were collected from 5 different spots, from which $\mathrm{I}_{\mathrm{D}} / \mathrm{I}_{\mathrm{G}}$ ratio was calculated and the average value is presented in Table 1. The samples were measured as prepared.

FT-IR measurements were performed on a Nicolet iS10 (Thermo Scientific) spectrometer. Before the sample measurement "dry air" background was recorded, which was subtracted automatically during registration of spectra for the investigated samples. The samples were mixed with $\mathrm{KBr}$ at a ratio of $1 / 300 \mathrm{mg}$, then compressed at $7 \mathrm{MPa} \mathrm{cm}^{-2}$ to form a pellet and the transmission spectrum was recorded. The spectra were collected in the range $400-4000 \mathrm{~cm}^{-1}$.

The electron microscope images were taken on a Hitachi S-5500 scanning electron microscope in secondary electrons (SE) mode.

\subsubsection{Degassing}

Degassing was performed in the Smart VacPrep (Micromeritics, USA). The samples of about $100 \mathrm{mg}$ were degassed under vacuum (about $10^{-2} \mathrm{mmHg}$ ) using a two-stage temperature program: (1) $90{ }^{\circ} \mathrm{C}$ for $1 \mathrm{~h}$, and (2) $300{ }^{\circ} \mathrm{C}$ for $24 \mathrm{~h}$. Degassing removed moisture and other volatile contaminants from the samples.

\subsubsection{Surface characterization}

The 3Flex Surface Characterization Analyzer (Micromeritics, USA) was used to examine the surface characteristics of GFs. All calculations were performed using the nitrogen adsorption isotherms determined at $-196{ }^{\circ} \mathrm{C}$. The BET surface area was calculated from a BET plot in the relative pressure range between 0.03 and 0.3535 that was determined using a procedure proposed by Rouquerol [24]. The micropore surface area was calculated using the t-plot method [25]. Porosity distribution was calculated using the Non-Local-Density-Functional Theory (NLDFT) with density-independent weights. The N2-DFT model was employed in the calculations assuming a slit-like pore geometry with the pore size range covered from 4.0 to $4000 \AA$ [26].

\subsubsection{Vapor adsorption}

A vapor source container (Micromeritics, USA) filled with n-hexane was used to carry out vapor adsorption on the degassed GF samples. The vapor source temperature was set at $40{ }^{\circ} \mathrm{C}$ and was controlled by the 3Flex with the heating mantle. Adsorption of n-hexane was performed at the temperature of $31^{\circ} \mathrm{C}$.

\section{Results and discussion}

\subsection{Sample characterization}

\subsubsection{Scanning electron microscopy}

The microscope images obtained for the graphene foams show that the surface of the samples is different for the materials before and after heating. In the sample GF $24 \mathrm{~h}$ (Fig. 1a, b) it can be seen that the surface of the sample is covered with small wrinkles. After heating (Fig. 1c, d) the surface of the sample becomes more rough, sharp edges of the graphene flakes become more visible and small spherical particles appear. This might be due to a partial reduction of graphene oxide during heating at $950{ }^{\circ} \mathrm{C}$. Reduced graphene oxide has lower oxygen group content which leads to a decrease in hydrogen bonding between separate flakes and the structure is not as ordered as for GO and it becomes more brittle. Small particles visible after heating can be also a result of GO reduction, during which oxygen groups are removed from bigger flakes leaving smaller carbon particles. A similar effect is observed also for samples GF $48 \mathrm{~h}$ (Fig. 1e, f) and Acrylic/GF 24 h (Fig. 1i, j) before and after heating (Fig. 1g, h and k, 1 respectively) of the graphene foams.

\subsubsection{Raman spectroscopy}

In Fig. 2, there are two exemplary Raman spectra presented for sample GF $24 \mathrm{~h}$ before (Fig. 2a) and after heating at $950{ }^{\circ} \mathrm{C}$ (Fig. 2b). For the other samples, the spectra were similar as for GF $24 \mathrm{~h}$ and GF $24 \mathrm{~h}-950 \mathrm{C}$ and were deconvoluted the same way. The obtained results allowed to specify the $\mathrm{D}$ and $\mathrm{G}$ modes position and $\mathrm{I}_{\mathrm{D}} / \mathrm{I}_{\mathrm{G}}$ ratio. The results are presented in Table 1. Raman spectra analysis exhibits, that the heating of the samples at $950{ }^{\circ} \mathrm{C}$ leads to the increase of the $\mathrm{I}_{\mathrm{D}} / \mathrm{I}_{\mathrm{G}}$ ratio. This might suggest an increase of the defect (carbon with $s p^{3}$ hybridization) concentration in the graphene foams after heating. Heating of the foams at $950{ }^{\circ} \mathrm{C}$ leads to pyrolysis of the polymers used for the preparation of Acrylic/GF graphene foams and might also result in the removal of oxygen functional groups present in the GO structure. Pyrolysis of the polymers leads to formation of mostly carbon with $s p^{3}$ hybridization (amorphous structure, which in Raman spectra will indicate a higher intensity of the $\mathrm{D}$ mode comparing to $\mathrm{G}$ mode which is observed for $s p^{2}$ carbon structures). Removal of oxygen groups not necessarily will restore the graphene structure and change the hybridization of carbon atoms (leaving $s p^{3}$ hybridization) present in the structure leading to a higher intensity of the D mode comparing to $\mathrm{G}$ mode. These results are in good agreement with the scanning electron microscopy measurements, 

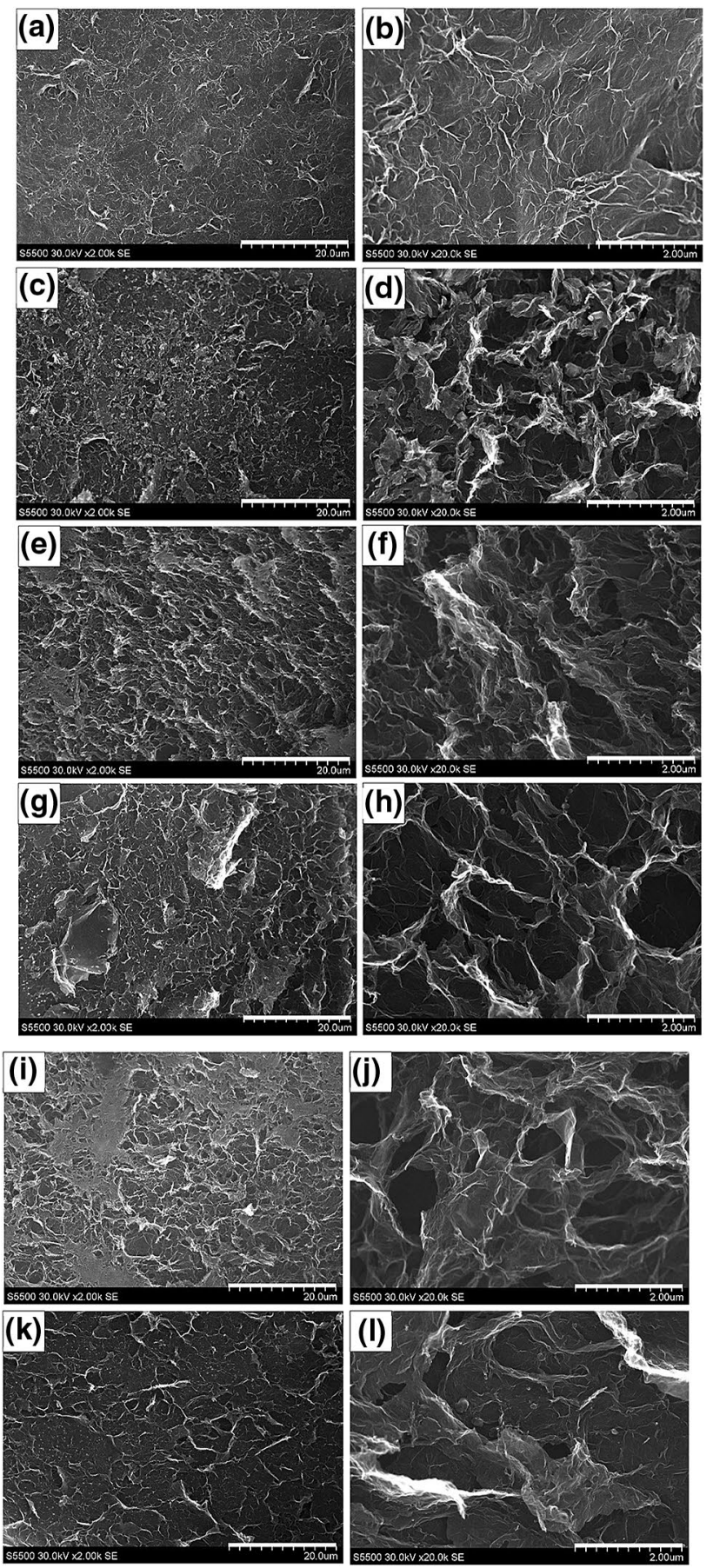

Fig. 1 SEM pictures of graphene foams: GF $24 \mathrm{~h}(\mathbf{a}, \mathbf{b})$, GF $24 \mathrm{~h}$ after heating at $950{ }^{\circ} \mathrm{C}(\mathbf{c}, \mathbf{d}), \mathrm{GF} 48 \mathrm{~h}(\mathbf{e}, \mathbf{f}), \mathrm{GF} 48 \mathrm{~h}$ after heating at $950{ }^{\circ} \mathrm{C}(\mathbf{g}, \mathbf{h})$, Acrylic/GF $24 \mathrm{~h}(\mathbf{i}, \mathbf{j})$ and Acrylic/GF $24 \mathrm{~h}$ after heating at $950{ }^{\circ} \mathrm{C}(\mathbf{k}, \mathbf{l})$

where the images show that after heating graphene foams have rougher structure indicating a higher defect density in the obtained samples.
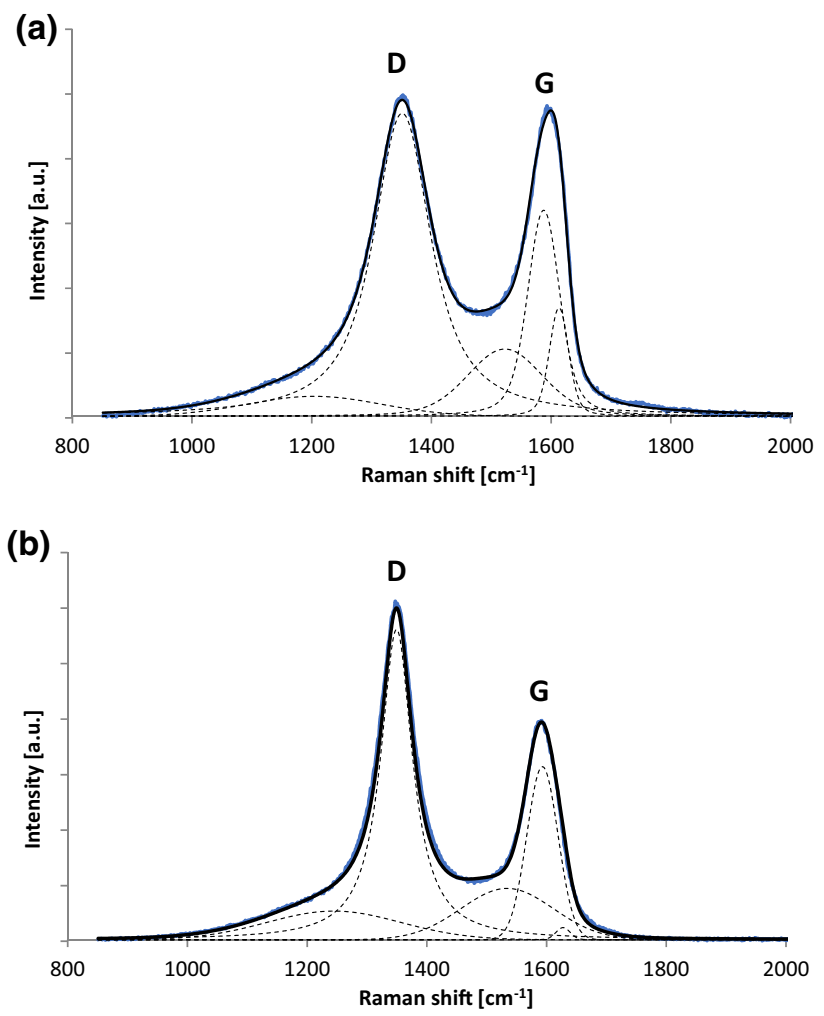

Fig. 2 Exemplary Raman spectra of foam GF $24 \mathrm{~h}$ before (a) and after (b) heating at $950{ }^{\circ} \mathrm{C}$

Table 1 Raman spectra analysis of the $\mathrm{D}$ and $\mathrm{G}$ modes position and $\mathrm{I}_{\mathrm{D}} / \mathrm{I}_{\mathrm{G}}$ ratio

\begin{tabular}{llll}
\hline & $\begin{array}{l}\text { D position } \\
\left(\mathrm{cm}^{-1}\right)\end{array}$ & $\begin{array}{l}\text { G position } \\
\left(\mathrm{cm}^{-1}\right)\end{array}$ & $\mathrm{I}_{\mathrm{D}} / \mathrm{I}_{\mathrm{G}}$ \\
\hline GF 24 h & 1353 & 1585 & 1.45 \\
GF 24 h-950C & 1349 & 1593 & 1.79 \\
GF 48 h & 1349 & 1584 & 1.21 \\
GF 48 h-950C & 1349 & 1595 & 1.64 \\
Acrylic/GF 24 h & 1345 & 1586 & 1.17 \\
Acrylic/GF 24 h-950C & 1344 & 1581 & 1.42 \\
\hline
\end{tabular}

\subsubsection{FT-IR spectroscopy}

As can be seen on the FT-IR spectra in Fig. 3, graphene oxide used for the preparation of the foams contains many functional groups. Mainly, they are hydroxyl $(-\mathrm{OH})$ groups found around $3500 \mathrm{~cm}^{-1}, \mathrm{C}-\mathrm{H}$ bonding found near $2900 \mathrm{~cm}^{-1}, \mathrm{C}=\mathrm{O}$ groups around $1700 \mathrm{~cm}^{-1}, \mathrm{C}=\mathrm{C}$ bonding around $1600 \mathrm{~cm}^{-1}$, and $\mathrm{C}-\mathrm{O}$ bonding near $1100 \mathrm{~cm}^{-1}$. It can be observed that the autoclave process for samples GF $24 \mathrm{~h}$ reduced most of the functional groups present in graphene oxide. The GF $48 \mathrm{~h}$ sample (spectrum not presented) exhibits the same chemical composition as sample GF $24 \mathrm{~h}$. On 
(a)

(a) 70

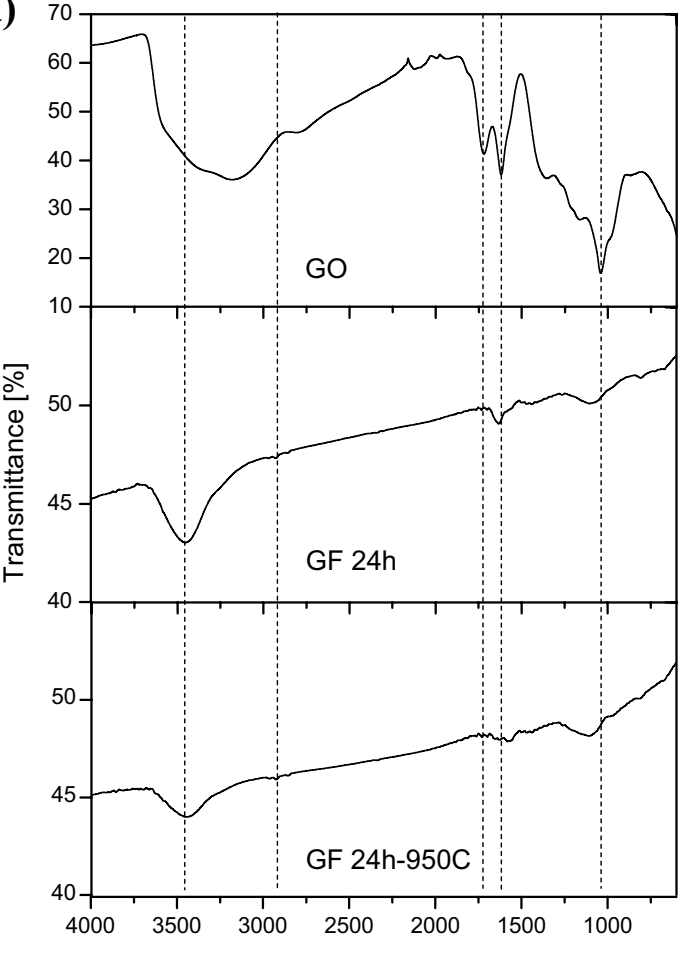

Wavenumber $\left[\mathrm{cm}^{-1}\right]$ (b)

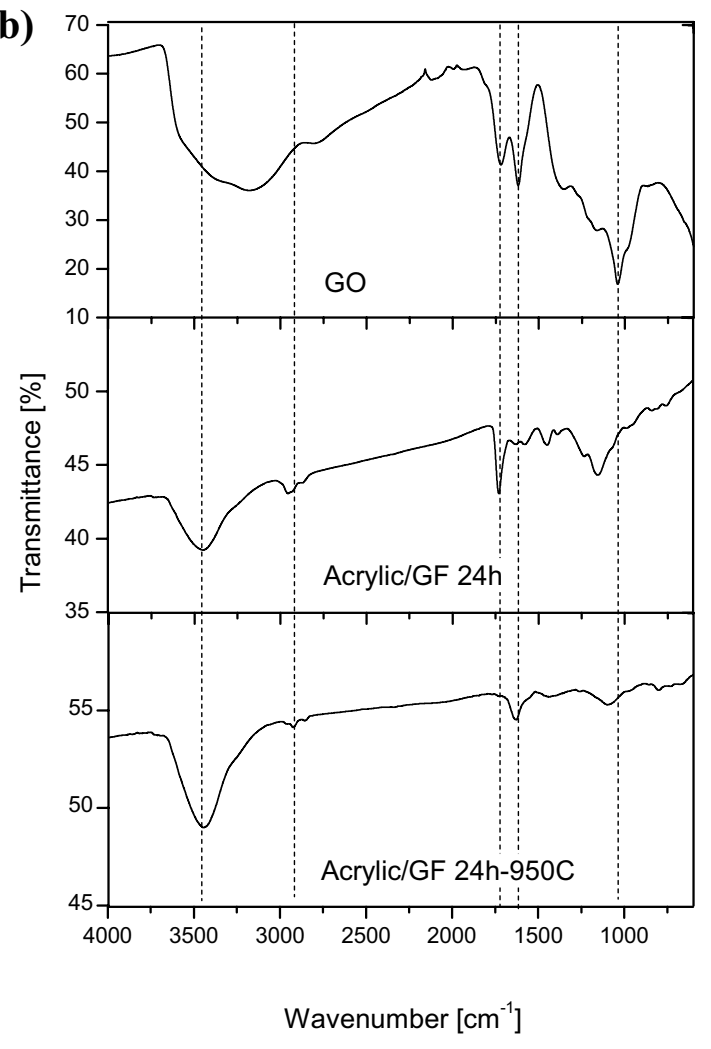

Fig. 3 FT-IR spectra of (a) graphene oxide, GF $24 \mathrm{~h}$ before and after heating, (b) graphene oxide, Acrylic/GF $24 \mathrm{~h}$ before and after heating

the FT-IR spectrum for the sample Acrylic/GF $24 \mathrm{~h}$ many functional groups are visible. This is due to the acrylic resin used for the preparation of this foam: mainly $\mathrm{C}-\mathrm{H}$ bonds can be observed in the range $2800-3000 \mathrm{~cm}^{-1}$ and around $1450 \mathrm{~cm}^{-1}, \mathrm{C}=\mathrm{O}$ groups are seen at around $1700 \mathrm{~cm}^{-1}$, $\mathrm{C}-\mathrm{O}-\mathrm{C}$ groups are visible at around $1100 \mathrm{~cm}^{-1}$. For all samples heating at $950{ }^{\circ} \mathrm{C}$ lead to defunctionalization of the obtained GFs.

\subsubsection{Surface characterization}

Figure 4 shows a comparison of the nitrogen isotherms performed at $-196{ }^{\circ} \mathrm{C}$ for the tested GFs. This analysis allows for determination of the porous structure of obtained GFs, especially micro- and mesopores, which are crucial for the adsorption of n-hexane. Interestingly, all presented isotherms, except that for Acrylic/GF $24 \mathrm{~h}$ sample, have similar shape. The adsorption branches are a composite of types I and II according to the IUPAC classification [27]. On the other hand, the adsorption branch of the Acrylic/GF $24 \mathrm{~h}$ sample resembles type II isotherm. Note that a true type II isotherm is reversible in the whole range of relative pressures. The pseudo-type II isotherms recognized for the tested GFs are reversible only in the lower relative pressure range. Similarly, the type H4 hysteresis loop has been identified for all GFs, except that for Acrylic/GF $24 \mathrm{~h}$ sample [27, 28]. Regarding the Acrylic/GF 24 h sample, the type H3 hysteresis loop has been found. In summary, with one exception regarding the Acrylic/GF $24 \mathrm{~h}$ sample, the initial reversible filling of micropores $(<2 \mathrm{~nm})$ is followed by multilayer adsorption and capillary condensation taking place in meso$(2-50 \mathrm{~nm})$ and macropores $(>50 \mathrm{~nm})$. Capillary condensation occurring in meso- and macropores can be seen as a hysteresis loop with a sharp increase of the adsorbed amount close to the saturation pressure. On the other hand, a pseudo-type II isotherm linked to the Acrylic/GF $24 \mathrm{~h}$ sample is characteristic for materials with pore diameters larger than micropores. Note also that only the Acrylic/ GF 24 h-950C sample has the typical steep region of the desorption branches closing the hysteresis loops at $P / P^{o}$ $\sim 0.42$. This is characteristic for the nitrogen hysteresis loops [27]. The other samples, except the Acrylic/GF $24 \mathrm{~h}$ sample, exhibit low pressure hysteresis which can be connected to the swelling of a non-rigid porous structure of GFs. In turn, the steep desorption branch at $P / P^{o} \sim 0.85$ for the Acrylic/GF $24 \mathrm{~h}$ sample reveals that the biggest pores can be expected. This might be connected to the fact 


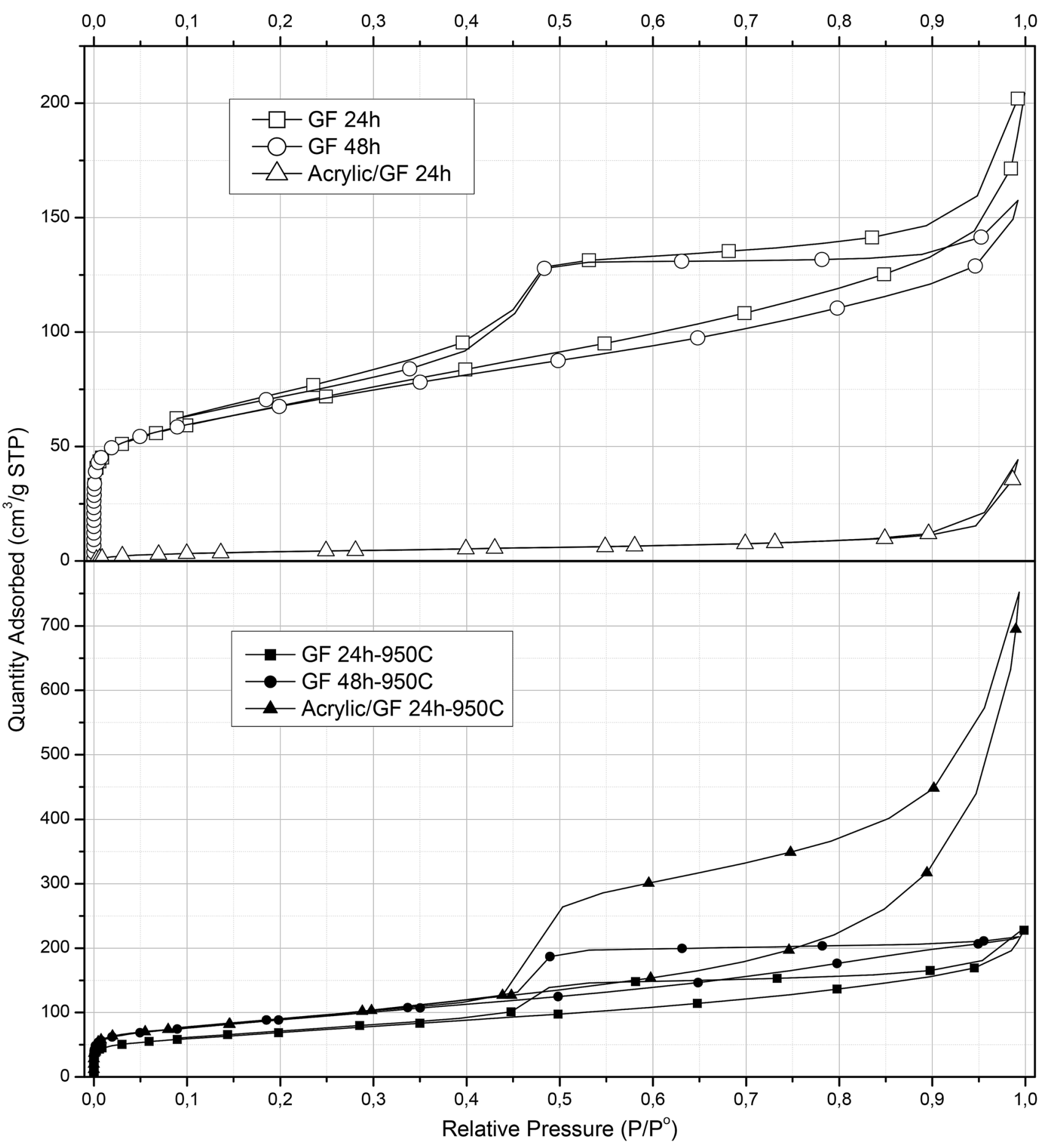

Fig. 4 Nitrogen adsorption at $-196{ }^{\circ} \mathrm{C}$ on the GFs

that acrylic polymer is still present in the graphene foam and is filling the pores. Both types $\mathrm{H} 3$ and $\mathrm{H} 4$ hysteresis loops are similar. The former has the adsorption branch being a pseudo-type II isotherm, while the latter has the adsorption branch being a composite of types I and II. The slit-like pores are associated with the $\mathrm{H} 3$ and $\mathrm{H} 4$ hysteresis loops.
Note that the types $\mathrm{H} 3$ and $\mathrm{H} 4$ hysteresis loops do not have a plateau at high relative pressures. Therefore, the pore size distribution in the mesopore range cannot be evaluated using classical methods based on the modified Kelvin equation, such as the Barrett-Joyner-Halenda (BJH) method. Instead, microscopic methods using statistical mechanics such as the NLDFT or Grand Canonical 


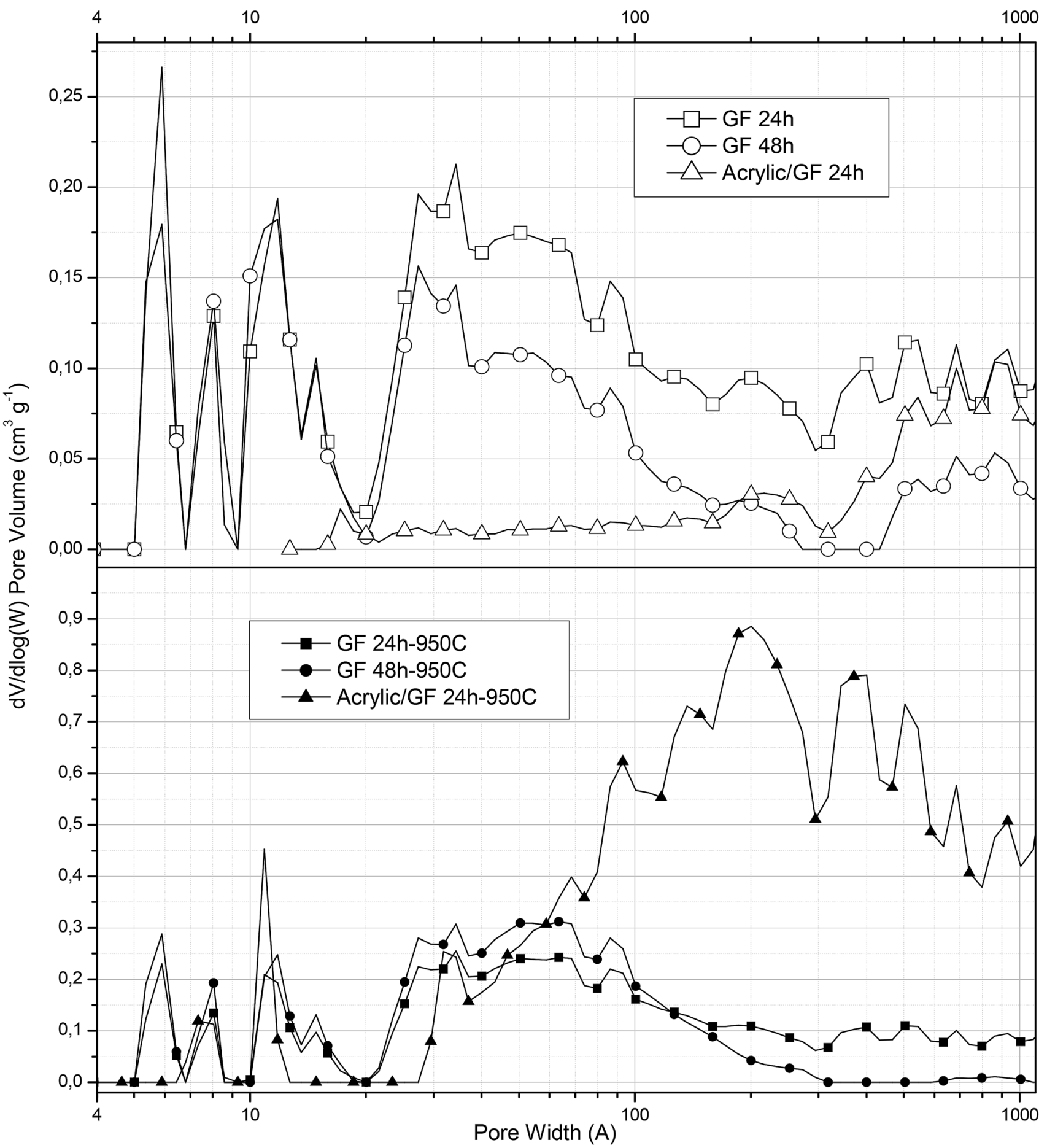

Fig. 5 Pore size distributions for the GFs calculated with the N2-DFT model

Monte Carlo can be applied. Using these methods an accurate pore size analysis over the complete micro- and mesopore size range is possible.

Figure 5 shows a comparison of the pore size distributions for all tested GFs. The distributions cover a wide range of the pore sizes from micropores up to the meso-macropore range
(>500 ̊). Again, all presented distributions, except that for Acrylic/GF $24 \mathrm{~h}$ sample, have some similarities. They display the porous structures in a wide range of pore widths. The presence of microporous structure is very beneficial for adsorption of small VOC molecules (critical diameter of n-hexane molecule is $4.9 \AA$ ). On the other hand, the presence 
of mesoporous structure can be critical for adsorption of larger molecules. In addition, mesopores are needed to provide adsorbates with access to the smallest pores. Regarding the Acrylic/GF $24 \mathrm{~h}$ sample, no micropores are identified and mesopores are practically absent. As stated earlier, this is possibly due to the filling of the pores with acrylic polymer. For the samples GF $24 \mathrm{~h}$ and GF $48 \mathrm{~h}$ there are slight differences in the amount of micro- and mesopores. Sample GF $24 \mathrm{~h}$ has a higher content of mesopores and lower of micropores comparing to GF $48 \mathrm{~h}$, which can be explained that due to extended drying the pores start to collapse from the hydrogen bonding between GO functional groups.

Table 2 summarizes the results on BET surface area, t-plot micropore area and total volume in pores for all GFs. As can be seen in Table 2, the BET surface area is higher for the heated GFs than the raw ones. This might be connected to partial reduction of graphene oxide forming a rougher structure, as can be seen from microscopic images. For the Acrylic/GF 24 h-950C sample, the polymer was pyrolyzed revealing the micro- and mesopores present in the structure. Additionally, pyrolyzed polymer residues could form new porous structure increasing the surface area of the sample.

Nitrogen isotherms at $-196{ }^{\circ} \mathrm{C}$ for different graphenebased adsorbents have been reported in the literature [10, $11,14,15,17,18,20,29]$. Remarkably, their shape and the shape of the isotherms obtained for our pyrolyzed GFs is the same. This reveals that such materials generally possess porous structure in a very wide range of sizes extending from micro- to macropores.

\subsubsection{Adsorption of $n$-hexane vapor}

Based on the surface characterization results adsorption of $n$-hexane was performed for graphene foams after heating at $950{ }^{\circ} \mathrm{C}$. Figure 6 shows a comparison of $n$-hexane isotherms determined at $31{ }^{\circ} \mathrm{C}$ for the pyrolyzed GFs. The Acrylic/GF $24 \mathrm{~h} 950{ }^{\circ} \mathrm{C}$ sample demonstrates the best performance among the three samples. There is full agreement with the results presented for nitrogen adsorption at $-196^{\circ} \mathrm{C}$ in Fig. 4. The surface area and total volume of pores of the Acrylic/GF 24 h-950C sample is the highest amongst the three analyzed samples. The Acrylic/ GF 24 h-950C sample shows the maximum amount adsorbed of $415 \mathrm{mg} \mathrm{g}^{-1}$ (after converting units from $\mathrm{cm}^{3}$ $\mathrm{g}^{-1}$ STP to $\mathrm{mg} \mathrm{g}^{-1}$ ). Comparing to the literature data this result is better than the maximum amount adsorbed for activated carbon derived from cork powder waste by $\mathrm{KOH}$ activation [30]. This activated carbon showed about $390 \mathrm{mg} \mathrm{g}^{-1}$ for the best sample (C800) prepared by mixing $1 \mathrm{~g}$ of $\mathrm{KOH}$ per $1 \mathrm{~g}$ of pretreated cork waste and calcinated at $800^{\circ} \mathrm{C}$. Another example where adsorption of n-hexane was also investigated was for metal-organic frameworks (MOF)/graphene oxide composites [31]. For this material the n-hexane uptake at $25^{\circ} \mathrm{C}$ was $1042 \mathrm{mg} \mathrm{g}^{-1}$, which is a higher value compared to our GFs. This is due to very beneficial textural properties of this material-BET surface area of $3502 \mathrm{~m}^{2} \mathrm{~g}^{-1}$ and total pore volume of $1.75 \mathrm{~cm}^{3} \mathrm{~g}^{-1}$.

On the other hand, another recent article on similar hybrid materials reports quite different adsorption capacities of n-hexane. Namely, rGO and three-dimensional graphene network (3DGN) were combined with ZIF-8 (ZIFs-zeolitic imidazolate frameworks) and UiO-66 (zirconium-based metal-organic frameworks) to increase their adsorption capacities [32]. Although these hybrid materials performed much better than pure ZIF-8 and UiO-66, they still had poorer $\mathrm{n}$-hexane adsorption capacities than our Acrylic/GF $24 \mathrm{~h}$ 950C sample. While the best ZIF8/3DGN sample adsorbed $4.26 \mathrm{mmol} \mathrm{g}^{-1}\left(367 \mathrm{mg} \mathrm{g}^{-1}\right)$ of n-hexane at 40 bars, the $n$-hexane adsorption capacity was lower than about $40 \mathrm{mg} \mathrm{g}^{-1}$ at 1 bar as follows from Fig. 1e in [32]. A comparison of separate results showing N2 uptake at $-196{ }^{\circ} \mathrm{C}$ on ZIF-8/3DGN (Fig. 2b in [32]) and the Acrylic/GF $24 \mathrm{~h} 950 \mathrm{C}$ sample (Fig. 4) confirms better $n$-hexane adsorption capacity of our sample. Note also that the use of metal-organic frameworks increases the cost of such materials, which makes it difficult to commercialize. Having that in mind, GFs prepared and studied in this paper have good adsorption of n-hexane with much lower costs compared to other studied adsorbents.
Table 2 Textural properties of the tested GFs

\begin{tabular}{llllll}
\hline Run no. & Sample name & $\begin{array}{l}\text { BET surface } \\
\text { area }\left(\mathrm{m}^{2} \mathrm{~g}^{-1}\right)\end{array}$ & $\begin{array}{l}\text { t-Plot micropore } \\
\text { area }\left(\mathrm{m}^{2} \mathrm{~g}^{-1}\right)\end{array}$ & & DFT \\
\cline { 5 - 6 } & & & & Pore size $(\AA)$ & $\begin{array}{l}\text { Total volume in } \\
\text { pores }\left(\mathrm{cm}^{3} \mathrm{~g}^{-1}\right)\end{array}$ \\
\hline 1 & GF 24 h & 240.0268 & 48.5221 & $\leq 4003.09$ & 0.28811 \\
2 & GF 24 h-950C & 244.9433 & 25.7369 & $\leq 4003.09$ & 0.32546 \\
3 & GF 48 h & 238.1401 & 63.8178 & $\leq 1475.96$ & 0.15249 \\
4 & GF 48 h-950C & 314.8579 & 30.6792 & $\leq 1720.79$ & 0.27307 \\
5 & Acrylic/GF 24 h & 15.3572 & - & $\leq 1475.96$ & 0.06329 \\
6 & Acrylic/GF 24 h-950C & 319.0186 & 13.4942 & $\leq 1858.04$ & 0.98202 \\
\hline
\end{tabular}




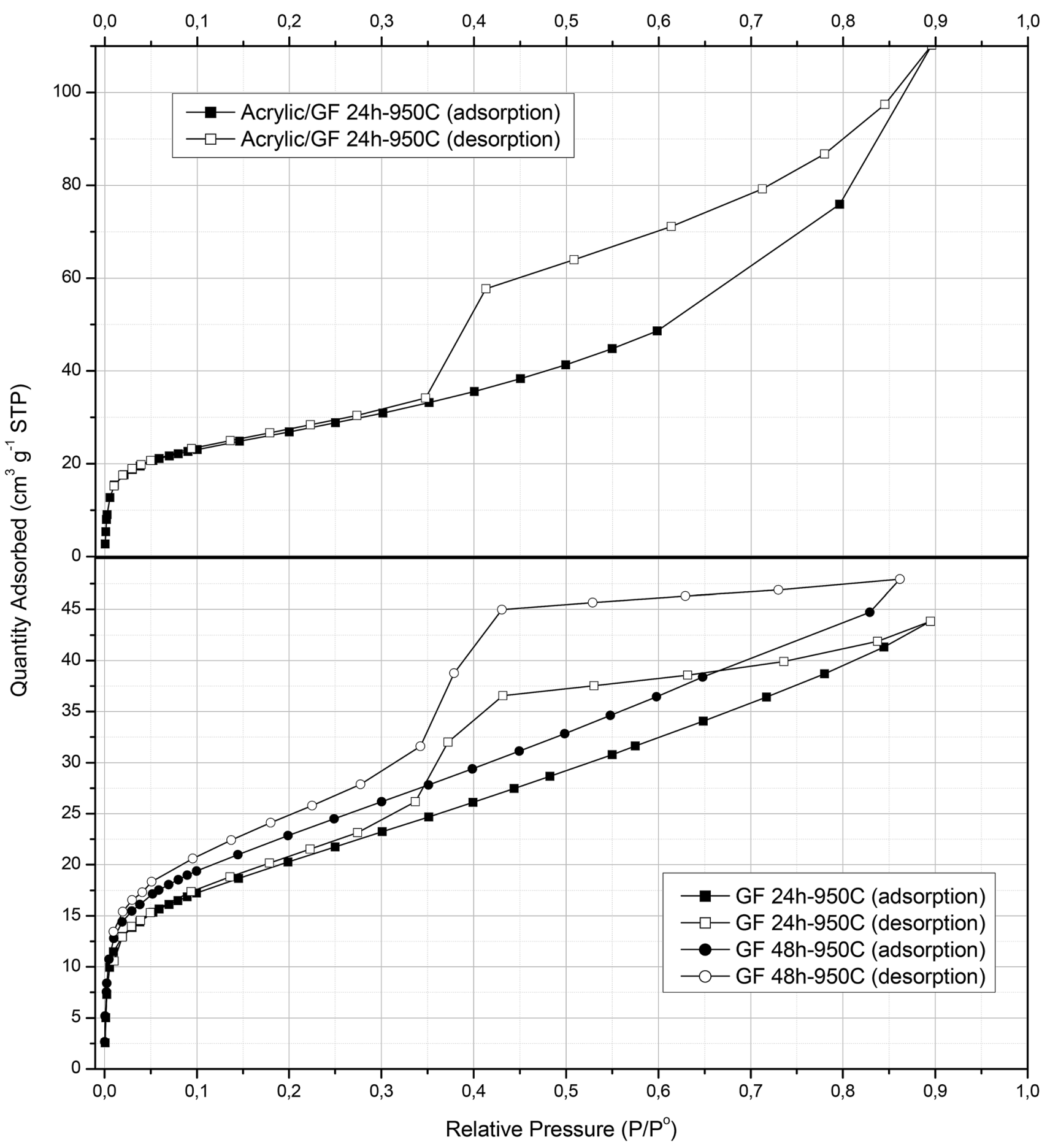

Fig. 6 n-Hexane adsorption at $31^{\circ} \mathrm{C}$ on the GFs

\section{Conclusions}

Various graphene foams were obtained from graphene oxide suspensions using different methods of foam preparation. Manufacturing conditions influenced the properties of the obtained graphene foams. The preparation conditions resulted in different structures of prepared graphene foams. Prolonged drying process of the hydrogel (sample GF $48 \mathrm{~h}$ ) resulted in higher amount of micropores and lower of mesopores. Addition of the acrylic polymer to GO suspension (Acrylic/GF $24 \mathrm{~h}$ ) resulted in the smallest surface area which was due to filling the pores with the polymer. Annealing the samples at $950{ }^{\circ} \mathrm{C}$ was responsible for defunctionalization of the obtained foams and pyrolyzation of the acrylic 
polymer. This resulted in an increase of the defects present in the carbon structure. The heating process increased the surface area and total volume in pores also in all the samples, which was used to test the graphene foams for adsorption of n-hexane. The tests have shown that the best sample for $\mathrm{n}$-hexane adsorption was the sample where for the preparation of the hydrogel acrylic resin was used. Sample Acrylic/ GF 24 h-950C adsorbed $415 \mathrm{mg} \mathrm{g}^{-1}$ of $\mathrm{n}$-hexane. The use of the acrylic microemulsion can lower the production costs of the graphene foams due to the fact that it is much cheaper than pure graphene and leads to a significant decrease of the used graphene for the preparation of the final product and its adsorption properties are enhanced. Comparing to the granular activated carbon graphene foams prepared with acrylic resin can be formed in desired shapes and have better mechanical properties, which makes them good candidates for preparing air filters with a large surface area. Additionally, these materials have also good acoustic and thermal insulation properties, which could be used for production of novel insulating materials with air purifying possibilities. Further tests on the preparation and modification of graphene foams could result in a significant increase of their adsorption properties and could be used for air purification in the future.

Acknowledgements The author A. M. thanks the National Centre for Research and Development for support of the Project LIDER/33/0117/L-9/17/NCBR/2018 and M.M.-P thanks for the support of the Project PL-TW III/4/2016.

Author contributions All authors contributed to the study conception and design. Material preparation, data collection and analysis were performed by AM, LS, M.M.-P and RC. The first draft of the manuscript was written by AM and MM-P all authors commented on previous versions of the manuscript. All authors read and approved the final manuscript.

Open Access This article is licensed under a Creative Commons Attribution 4.0 International License, which permits use, sharing, adaptation, distribution and reproduction in any medium or format, as long as you give appropriate credit to the original author(s) and the source, provide a link to the Creative Commons licence, and indicate if changes were made. The images or other third party material in this article are included in the article's Creative Commons licence, unless indicated otherwise in a credit line to the material. If material is not included in the article's Creative Commons licence and your intended use is not permitted by statutory regulation or exceeds the permitted use, you will need to obtain permission directly from the copyright holder. To view a copy of this licence, visit http://creativecommons.org/licenses/by/4.0/.

\section{References}

1. Y. Zhu, S. Murali, M.D. Stoller, K.J. Ganesh, W. Cai, P.J. Ferreira, A. Pirkle, R.M. Wallace, K.A. Cychosz, M. Thommes, D. Su, E.A. Stach, R.S. Ruoff, Carbon-based supercapacitors produced by activation of graphene. Science 332, 1537-1542 (2011). https ://doi.org/10.1126/science. 1200770

2. U. Khan, A. O'Neill, M. Lotya, S. De, J.N. Coleman, Highconcentration solvent exfoliation of graphene. Small 6, 864-871 (2010). https://doi.org/10.1002/smll.200902066

3. W.S. Hummers, R.E. Offeman, Preparation of graphitic oxide. J. Am. Chem. Soc. 80, 1339 (1958). https://doi.org/10.1021/ja015 $39 \mathrm{a} 017$

4. B. Lesiak, L. Stobinski, A. Malolepszy, M. Mazurkiewicz, L. Kövér, J. Tóth, Preparation of graphene oxide and characterisation using electron spectroscopy. J. Electron Spectros. Relat. Phenom. 193, 92-99 (2014). https://doi.org/10.1016/j.elspec.2014.03.015

5. L. Stobinski, B. Lesiak, A. Malolepszy, M. Mazurkiewicz, B. Mierzwa, J. Zemek, P. Jiricek, I. Bieloshapka, Graphene oxide and reduced graphene oxide studied by the XRD, TEM and electron spectroscopy methods. J. Electron Spectros. Relat. Phenom. 195, 145-154 (2014). https://doi.org/10.1016/j.elspec.2014.07.003

6. B. Lesiak, G. Trykowski, J. Tóth, S. Biniak, L. Kövér, N. Rangam, L. Stobinski, A. Malolepszy, Chemical and structural properties of reduced graphene oxide-dependence on the reducing agent. J. Mater. Sci. (2020). https://doi.org/10.1007/s10853-020-05461 $-1$

7. The European Parliament and the Council of the European Union, DIRECTIVE 2004/42/CE OF THE EUROPEAN PARLIAMENT AND OF THE COUNCIL of 21 April 2004 on the limitation of emissions of volatile organic compounds due to the use of organic solvents in certain paints and varnishes and vehicle refinishing products and amendi, Off. J. Eur. Union. L 143, 87-96 (2004)

8. THE EUROPEAN PARLIAMENT AND THE COUNCIL OF THE EUROPEAN UNION, DIRECTIVE 2010/75/EU OF THE EUROPEAN PARLIAMENT AND OF THE COUNCIL of 24 November 2010 on industrial emissions (integrated pollution prevention and control), Off. J. Eur. Union. L 334, 17-119 (2010)

9. A. Ganesan, M.M. Shaijumon, Activated graphene-derived porous carbon with exceptional gas adsorption properties. Microporous Mesoporous Mater. 220, 21-27 (2016). https://doi.org/10.1016/j. micromeso.2015.08.021

10. G. Srinivas, J. Burress, T. Yildirim, Graphene oxide derived carbons (GODCs): synthesis and gas adsorption properties. Energy Environ. Sci. 5, 6453-6459 (2012). https://doi.org/10.1039/c2ee2 $1100 \mathrm{a}$

11. J.M. Kim, J.H. Kim, C.Y. Lee, D.W. Jerng, H.S. Ahn, Toluene and acetaldehyde removal from air on to graphene-based adsorbents with microsized pores. J. Hazard. Mater. 344, 458-465 (2018). https://doi.org/10.1016/j.jhazmat.2017.10.038

12. Y. He, N. Zhang, F. Wu, F. Xu, Y. Liu, J. Gao, Graphene oxide foams and their excellent adsorption ability for acetone gas. Mater. Res. Bull. 48, 3553-3558 (2013). https://doi.org/10.1016/j.mater resbull.2013.05.056

13. G.Q. Liu, M.X. Wan, Z.H. Huang, F.Y. Kang, Preparation of graphene/metal-organic composites and their adsorption performance for benzene and ethanol. Xinxing Tan Cailiao/New Carbon Mater. 30, 566-571 (2015). https://doi.org/10.1016/S1872 $-5805(15) 60205-0$

14. Z. Guo, J. Huang, Z. Xue, X. Wang, Electrospun graphene oxide/ carbon composite nanofibers with well-developed mesoporous structure and their adsorption performance for benzene and butanone. Chem. Eng. J. 306, 99-106 (2016). https://doi. org/10.1016/j.cej.2016.07.048

15. L. Yu, L. Wang, W. Xu, L. Chen, M. Fu, J. Wu, D. Ye, Adsorption of VOCs on reduced graphene oxide. J. Environ. Sci. (China) 67, 171-178 (2018). https://doi.org/10.1016/j.jes.2017.08.022

16. B. Szczęśniak, J. Choma, M. Jaroniec, Effect of graphene oxide on the adsorption properties of ordered mesoporous carbons toward $\mathrm{H}_{2}, \mathrm{C}_{6} \mathrm{H}_{6}, \mathrm{CH}_{4}$ and $\mathrm{CO}_{2}$. Microporous Mesoporous 
Mater. 261, 105-110 (2018). https://doi.org/10.1016/j.micro meso.2017.10.054

17. A.B. Bourlinos, T.A. Steriotis, M. Karakassides, Y. Sanakis, V. Tzitzios, C. Trapalis, E. Kouvelos, A. Stubos, Synthesis, characterization and gas sorption properties of a molecularly-derived graphite oxide-like foam. Carbon N. Y. 45, 852-857 (2007). https ://doi.org/10.1016/j.carbon.2006.11.008

18. S. Gadipelli, Z.X. Guo, Graphene-based materials: synthesis and gas sorption, storage and separation. Prog. Mater. Sci. 69, 1-60 (2015). https://doi.org/10.1016/j.pmatsci.2014.10.004

19. L. Mahmoudian, A. Rashidi, H. Dehghani, R. Rahighi, Single-step scalable synthesis of three-dimensional highly porous graphene with favorable methane adsorption. Chem. Eng. J. 304, 784-792 (2016). https://doi.org/10.1016/j.cej.2016.07.015

20. Y. Zhou, L. Zhou, X. Zhang, Y. Chen, Preparation of zeolitic imidazolate framework-8/graphene oxide composites with enhanced VOCs adsorption capacity. Microporous Mesoporous Mater. 225, 488-493 (2016). https://doi.org/10.1016/j.micro meso.2016.01.047

21. CRC Handbook of Chemistry and Physics. 91st ed. CRC Press Inc., Boca Raton, FL pp. 3-282 (2010-2011)

22. R.R. Arnts, S.A. Meeks, Biogenic hydrocarbon contribution to the ambient air of selected areas. Atmos. Environ. 15, 1643-1651 (1981)

23. C. Pastore, D. Marhuenda, J. Marti, A. Cardona, Early diagnosis of n-hexane-caused neuropathy. Muscle Nerve 17, 981-986 (1994). https://doi.org/10.1002/mus.880170904

24. J. Rouquerol, P. Llewellyn, F. Rouquerol, Is the bet equation applicable to microporous adsorbents? Stud. Surf. Sci. Catal. (2007). https://doi.org/10.1016/S0167-2991(07)80008-5

25. M. Lowell, S. Shields, J.E. Thomas, M.A. Thommes, Characterization of Porous Solids and Powders: Surface Area Pore Size and Density (Springer, Amsterdam, 2004).

26. Micromeritics Instrument Corporation 2013-2014, 3FLEX Surface Characterization Analyzer-Operator Manual (2014)
27. K.S.W. Sing, D.H. Everett, R.A.W. Haul, L. Moscou, R.S. Pierotti, J. Rouquerol, T. Siemieniewska, International Union of Pure Commission on Colloid and Surface Chemistry Including CatalysisReporting physisorption data for gas/solid systems with special reference to the determination of surface area and porosity. Pure Appl. Chem. 57, 603-619 (1985). https://doi.org/10.1351/pac19 8557040603

28. M. Thommes, K. Kaneko, A.V. Neimark, J.P. Olivier, F. Rodriguez-Reinoso, J. Rouquerol, K.S.W. Sing, Physisorption of gases, with special reference to the evaluation of surface area and pore size distribution (IUPAC Technical Report). Pure Appl. Chem. 87, 1051-1069 (2015). https://doi.org/10.1515/pac-2014-1117

29. S. Chowdhury, R. Balasubramanian, Three-dimensional graphenebased porous adsorbents for postcombustion $\mathrm{CO}_{2}$ capture. Ind. Eng. Chem. Res. 55, 7906-7916 (2016). https://doi.org/10.1021/ acs.iecr.5b04052

30. B. Cardoso, A.S. Mestre, A.P. Carvalho, J. Pires, Activated carbon derived from cork powder waste by $\mathrm{KOH}$ activation: preparation, characterization, and VOCs adsorption. Ind. Eng. Chem. Res. 47, 5841-5846 (2008). https://doi.org/10.1021/ie800338s

31. X. Sun, Q. Xia, Z. Zhao, Y. Li, Z. Li, Synthesis and adsorption performance of MIL-101(Cr)/graphite oxide composites with high capacities of n-hexane. Chem. Eng. J. 239, 226-232 (2014). https ://doi.org/10.1016/j.cej.2013.11.024

32. Y. Sun, M. Ma, L. Jiang, X. Sun, M. Que, C. Tao, Z. Wu, High n-hexane adsorption capacity of composite adsorbents based on MOFs and graphene with various morphologies. Ind. Eng. Chem. Res. 59, 13744-13754 (2020). https://doi.org/10.1021/acs. iecr.0c02128

Publisher's Note Springer Nature remains neutral with regard to jurisdictional claims in published maps and institutional affiliations. 